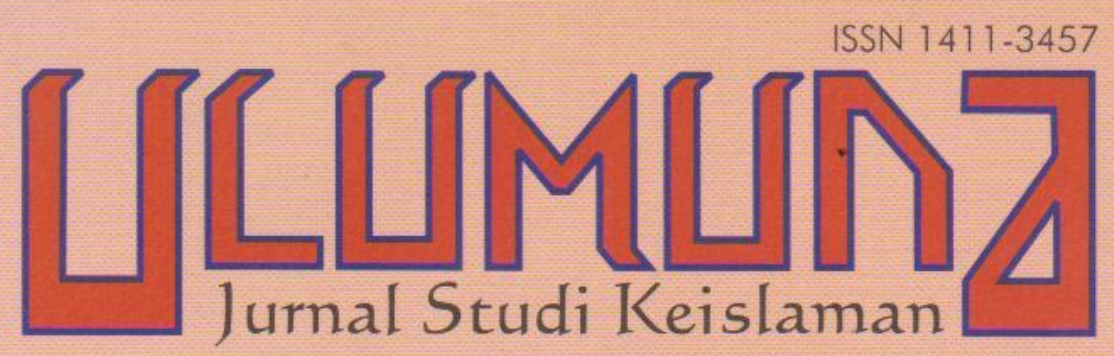

Volume XII• Nomor 1• Juni 2008

STUDI ANALITIS DIMENSI SACIFACT PENDIDIKAN ISLAM PADA MASA KEJAYAANNYA (750-1258 M) Abdul Fattah

AKTUALISASI MANUSIA VERSI AL-QUR'AN: ANTARA IDEALITAS DAN REALITAS PENDIDIKAN ISLAM Ismail Thoib

PENDIDIKAN ISLAM DAN PENCERAHAN SPIRITUALITAS: IKHTIAR MENJAWAB TANTANGAN POSMODERNISME Suparta

LESSON STUDY DALAM PEMBELAJARAN AGAMA ISLAM DI SEKOLAH UMUM Ahmad Munjin dan Khoirul Adib

STUDI PERUBAHAN KELEMBAGAAN DAN METODOLOGI PADA MADRASAH MODEL Taufik Churahman dan Musfigon POSISI PEREMPUAÑ
PERSPEKTIF ULAMA KLASIK
Baehaqi 


\section{PEDOMAN TRANSLITERASI}

\begin{tabular}{|c|c|c|c|}
\hline Arab & Latin & Arab & Latin \\
\hline 1 & $=$ & ف & $=\mathbf{f}$ \\
\hline ب & $=$ & ق & $=\mathrm{q}$ \\
\hline$\dot{H}$ & $=$ & ك & $=\mathbf{k}$ \\
\hline 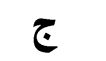 & $=$ & $J$ & $=1$ \\
\hline$\tau$ & $=$ & s & $=\mathrm{m}$ \\
\hline$\dot{\tau}$ & $=\quad \mathbf{k h}$ & $\dot{~ ن}$ & $=\mathbf{n}$ \\
\hline$د$ & $=$ & و & $=\mathbf{w}$ \\
\hline$\dot{j}$ & $d z$ & o & $=h$ \\
\hline J & $=$ & $\varepsilon$ & $=$, \\
\hline j & $=$ & 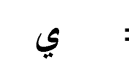 & $=y$ \\
\hline س - س & $=$ & & \\
\hline ش & $=$ & \multirow{2}{*}{\multicolumn{2}{|c|}{$\begin{array}{l}\text { Untuk Madd } \\
\text { dan Diftong }\end{array}$}} \\
\hline ص & sh & & \\
\hline ض & dl & i & $=$ â (a panjang) \\
\hline b & th & = & $=\hat{\mathbf{i}}(\mathbf{i}$ panjang) \\
\hline ظ & $\mathbf{z h}$ & أوز & $=\quad \hat{\mathbf{u}}$ (u panjang) \\
\hline$\varepsilon$ & $=$ & آون & $=\mathbf{a w}$ \\
\hline$\dot{\varepsilon}$ & $=\mathrm{gh}$ & = & $=a y$ \\
\hline
\end{tabular}




\section{ISI}

TRANSLITERASI

ANTARAN

UTAMA

Abdul Fattah

Studi Analitis Dimensi Sacifact Pendidikan Islam pada Masa Kejayaannya $(750-1258 \mathrm{M}) \bullet 1-28$

Ismail Thoib

Aktualisasi Manusia Versi Al-Qur'an:

Antara Idealitas dan Realitas

Pendidikan Islam • 29-46

Suparta

Pendidikan Islam dan Pencerahan

Spiritualitas: Ikhtiar Menjawab Tantangan

Posmodernisme • 47-66

Ahmad Munjin Nasih Lesson Study dalam Pembelajaran

dan Khoirul Adib Pendidikan Agama Islam

di Sekolah Umum • 67-88

Taufik Churahman Dinamika Pendidikan Islam: Studi

dan Musfiqon

Perubahan Kelembagaan dan Metodologi

pada Madrasah Model • 89-106

LEPAS

Mutawalli Pembaruan Hukum Islam:

Menimbang Tawaran Pemikiran

'Abd al-Lâh al-Na'îm • 107-128

Baehaqi Posisi Perempuan

Perspektif Ulama Klasik • 129-142

Ahmad Sulhan Islam Kontemporer: Antara Reformasi

dan Revolusi Peradaban • 143-156

Ahmad Choirul Rofiq Menilai Kompetensi al-Mâturîdî di Bidang

Tafsir al-Qur'an • 157-182

ULAS BUKU

Yayuk Fauziyah Menyingkap Kuasa Maskulinitas di Balik

Tabir Feminitas Wanita Jawa • 183-200

INDEKS 


\title{
DINAMIKA PENDIDIKAN ISLAM: \\ STUDI PERUBAHAN KELEMBAGAAN \\ DAN METODOLOGI PADA MADRASAH MODEL
}

\author{
Taufik Churahman \\ Musfiqon*
}

\begin{abstract}
In this article, I study Islamic education developing in undulated ways from the classic to modern era, including in Indonesia. There is dynamics in two cases: institution and methodology. In term of institutional dynamics, Islamic educational institutions are established through three phases: mosques, Khan Mosques and madrasahs. In Indonesia, madrasahs are formed from teaching and learning in Muslim leaders' (kiyais) houses, mosques, Islamic boarding schools (pesantren) and then madrasahs. In term of methodological dynamics, Islamic education in madrasahs is started from lecture, memorization, and open discussion. In Indonesia, the developed methods are lecture given through sorogan, bandongan, and classical ways. Those institutional and methodological dynamics bring about madrasahs have special characteristics as particular Islamic educational institutions. As a result, excellent and model madrasahs bave been established recently.
\end{abstract}

Keywords: Dinamika Kelembagaan, Metodologi, Madrasah, Kurikulum, Pesantren.

DALAM sejarah peradaban Islam, pendidikan Islam telah berlangsung sejak Nabi Muhammad saw. diutus menjadi rasul Allah, sehingga perjalanan pendidikan Islam terjadi sejak Nabi

*Penulis adalah mahasiswa Pascasarjana $\left(\mathrm{S}_{3}\right)$ IAIN Sunan Ampel Surabaya, Jln. Jend. A. Yani 117 Surabaya. email: triamoko@yahoo.com 
Muhammad saw. mengajarkan nilai-nilai Islam dalam kehidupan umat saat itu. Dinamika pendidikan Islam pun berlangsung secara progresif, terutama pada masa klasik pada tiga periode pertama (sekitar tahun 650-1000 Masehi), yaitu pada masa kejayaan Islam. Dinamika pendidikan Islam masa klasik terus berkembang hingga zaman modern dengan berbagai dinamika dan bentuknya.

Ada dua fenomena dinamika pendidikan Islam yang berlangsung secara fluktuatif, yaitu dinamika kelembagaan dan dinamika metodologi. Dua fenomena ini telah menjadi fokus kajian para pemikir Islam dari masa ke masa. Dalam kurun waktu tersebut, lembaga pendidikan Islam mengalami perubahan. Mulai dari pengelolaan, tempat pembelajaran, hingga metode pembelajaran yang digunakan.

Perubahan ini berlangsung hingga zaman modern, tepatnya pada akhir abad XIX dan semakin berkembang pada periode setelahnya. Pada masa ini institusi pendidikan Islam mulai beradaptasi dengan perkembangan dunia. Sebab masa kejayaan Islam (The Islam's Golden Age) juga terkait dengan pemikiran modernis. ${ }^{1}$ Bahkan pada masa modern ini progresivitas lembaga pendidikan Islam mengalami perkembangan pesat sehingga perubahan kelembagaan dan metodologi yang terjadi sangat beragam. Perubahan ini juga memunculkan fenomena dan fakta tersendiri dalam konteks pendidikan Islam di madrasah. Salah satu indikator tentang hal ini adalah munculnya model pengelolaan madrasah yang beragam.

Dinamika institusi pendidikan Islam ini juga terjadi di Indonesia yang sejak awal telah mengembangkan pendidikan Islam. Dalam sejarahnya, pendidikan Islam di Indonesia berlangsung sejak masuknya Islam ke Indonesia, yaitu sekitar abad XVI atau XVII M. Ini artinya bahwa pendidikan Islam telah berlangsung dalam kurun waktu yang cukup lama di

1John L. Esposito, The Oxford Encyclopedia of the Modern Islamic World (New York: Oxford University, 1995), 118. 
Indonesia. Keberadaannya pun telah memunculkan perubahanperubahan yang perlu dikaji secara ilmiah.

Pada awalnya, pendidikan Islam di Indonesia dilakukan dalam bentuk kajian di masjid, pondok pesantren, lalu menjadi madrasah setelah mengalami perjalanan panjang. ${ }^{2}$ Namun dalam perjalanan sejarah pendidikan di Indonesia, kelembagaan dalam bentuk institusi pesantren maupun madrasah juga mengalami aneka perubahan. Dalam pada itu, seiring perkembangan zaman, pola pengelolaan dan manajemen madrasah terus mengalami perubahan, baik dari sisi institusi maupun metodologinya. Pendidikan Islam menjadi dinamis karena perubahan-perubahan yang terus berlangsung.

Dari sisi institusi, madrasah mengalami perubahan bentuk pengelolaan dan memunculkan model pendidikan Islam di madrasah yang jauh berbeda dengan zaman perintisannya. Ada madrasah unggulan, madrasah model, madrasah bertaraf internasional serta lainnya. Perubahan institusi ini ternyata mempengaruhi perubahan metodologi pendidikan Islam di madrasah. Metodologinya pun dikembangkan dengan lebih dinamis menyesuaikan perkembangan zaman.

Dalam konteks Indonesia, madrasah mulai dikenal pada awal abad XX dengan format yang berbeda dengan perkembangan dan bentuk madrasah yang ada di Timur Tengah. Istilah madrasah di Indonesia tidak diketahui secara pasti kapan diterapkan. ${ }^{3}$

Tulisan ini bertujuan untuk mengkaji dan menganalisis perubahan madrasah yang dimanis tersebut. Kajian difokuskan pada abad modern dan dikhususkan pada dinamika madrasah di Indonesia. Bahasan ini dipandang menarik dan penting dalam rangka mengeksplorasi dinamika madrasah yang telah memunculkan fenomena dan fakta sejarah dari eksistensinya

2Ibid., 15.

${ }^{3}$ Maksum, Madrasah: Sejarah dan Perkembangannya (Jakarta: Logos Wacana Ilmu, 1999), 97. 
serta untuk mengidentifikasi dan menemukan alternatif model madrasah yang adaptif sesuai perkembangan zaman.

\section{Konsep Pendidikan Islam}

Dalam Islam, pendidikan disebut dengan ta'dîh. Kata ta'dî́ mengarah pada pengertian yang lebih tinggi, dan mencakup unsur-unsur pengetahuan ('ilm), pengajaran (ta'lim) dan pengasuhan yang baik (tarbiyah). Kemudian istilah ta'dî́b mulai tidak dikenal lagi dan istilah tarbiyah lebih dikenal dalam dunia Islam sebagai pendidikan Islam.

Banyak definisi yang diajukan para pakar tentang pendidikan Islam. Masing-masing definisi memiliki relevansi dan kesamaan makna secara hakiki meskipun beragam bahasa yang digunakan. Definisi pendidikan secara umum itu sendiri adalah bimbingan secara sadar oleh pendidik terhadap perkembangan jasmani dan rohani peserta didik menuju terbentuknya kepribadian yang utama agar menjadi manusia dewasa yang bertanggung jawab. Dengan demikian pendidikan dipandang sebagai salah satu aspek yang memiliki peranan pokok dalam membentuk generasi muda yang dewasa agar memiliki kepribadian yang baik dan utama.

Menurut Syed Muhammad al-Naquib al-Attas, dalam mendefinisikan pendidikan Islam mempertentangkan istilah tarbiyah, ta'lîm dan ta'dîb. Tarbiyah berarti membesarkan, tanpa mencakup penanaman pengertian dalam proses itu. Sedangkan istilah ta'lim adalah mengajar (pengajaran), yaitu transfer ilmu pengetahuan. Adapun kata ta'dî́ adalah disiplin tubuh, jiwa, dan ruh. Disiplin yang dimaksud adalah menegaskan pada pengenalan pengakuan tempat yang tepat dalam hubungannya dengan kemampuan dan potensi jasmaniah, intelektual, dan rohaniah. Dari istilah-istilah itu beliau menyatakan bahwa istilah tarbiyah tidak tepat diterapkan, karena sempit jangkauannya dan terlalu khusus sifatnya. ${ }^{4}$

${ }^{4}$ Imam Bawani dan Isa Anshori, Cendekiawan Muslim dalam Perspektif 
Sedangkan menurut Abdul Fattah Jalal, istilah ta'lîm lebih tepat digunakan dalam memberikan pengertian pendidikan Islam, dan ia tidak sependapat dengan kata tarbiyah karena jika kata tersebut diterapkan maka pendidikan Islam hanya terbatas pada pemenuhan kebutuhan biologis dan moral tanpa memberikan ilmu dalam pengertian yang lebih luas. ${ }^{5}$

M. Yusuf al-Qardhawi memberikan pengertian bahwa pendidikan Islam adalah pendidikan manusia seutuhnya, baik dari segi akal dan hatinya, ruhani dan jasmaninya, akhlaq dan ketrampilannya. ${ }^{6}$ Sementara menurut Abdurrahman Saleh, pendidikan agama Islam (PAI) adalah usaha berupa bimbingan dan asuhan terhadap anak didik supaya setelah lulus dari pendidikannya dapat memahami dan mengamalkan ajaran-ajaran Islam serta menjadikannya sebagai way of life. ${ }^{7}$ Menurut Ahmad D. Marimba, pendidikan Islam adalah bimbingan jasmani, rohani berdasarkan hukum-hukum Islam menuju kepada terbentuknya kepribadian utama menurut ukuran-ukuran Islam. Dalam pengertian yang lain seringkali dikatakan bahwa kepribadian utama itu diistilahkan dengan "kepribadian muslim", yaitu kepribadian yang memiliki nilai-nilai Islami, memilih dan memutuskan serta berbuat berdasarkan nilai-nilai Islam, dan bertanggung jawab sesuai dengan nilai-nilai Islam. ${ }^{8}$

Dari berbagai pengertian pendidikan agama Islam di atas, dapat disimpulkan bahwa yang dimaksud dengan pendidikan agama Islam adalah suatu proses penggairahan, pembentukan, pendayagunaan, dan pengembangan fikir, zikir, dan kreasi

Pendidikan Islam (Surabaya: Bina Ilmu, 1991), 72-3.

${ }^{5}$ Ibid., 74-5.

'Yusuf Qardhawi, Pendidikan Islam dan Madrasah Hasan al-Banna, terj. Bustani A. Ghani dan Zainal Abidin Ahmad (Jakarta:Bulan Bintang, 1980), 157. 10.

7Zuhairini (et. al.), Metodologi Pendidikan Agama (Solo: Ramadhani, 1993),

${ }^{8}$ Ahmad D. Marimba, Pengantar Filsafat Pendidikan Islam (Bandung: alMa'arif, 1981), 23. 
manusia melalui usaha pengajaran, bimbingan, latihan, dan pengabdian yang dilandasi dan dinafasi oleh nilai-nilai ajaran Islam sehingga terbentuk pribadi muslim sejati yang mampu mengontrol, mengatur, dan merekayasa kehidupan serta dilakukan sepanjang zaman dengan penuh tanggung jawab, dan semata-mata untuk beribadah kepada Allah swt.

Dalam sistem pendidikan, suatu masalah yang sangat fundamental dalam melaksanakan kegiatan operasionalnya adalah "dasar" dari pendidikan itu, karena akan menentukan corak dan isi pendidikan yang berupa kurikulum. Secara terminologi, dasar adalah sesuatu yang dipakai sebagai landasan dalam berpijak, dan dari sanalah segala aktivitas yang berdiri di atasnya akan dijiwai dan diwarnai. ${ }^{9}$ Menurut Ahmad D. Marimba, pengertian dasar yang dianalogikan pada suatu bangunan adalah "bagian dari bangunan yang menjadi sumber kekuatan dan keteguhan tetap berdirinya bangunan itu". ${ }^{10}$ Jadi jelaslah bahwa yang dimaksud dengan dasar pendidikan adalah suatu landasan yang dijadikan pegangan dalam menyelenggarakan pendidikan yang berorientasi pada pandangan hidup dan falsafah hidupnya.

Sementara dalam konteks pendidikan agama Islam, maka "dasar" itu identik dengan sumber ajaran Islam, karena keduanya sama-sama bersumber dari al-Qur'an dan hadis. Pada tataran selanjutnya dikembangkan pemahaman para ulama dengan pandangan-pandangan mereka dalam bentuk qiyas syar'i dan ijma' yang diakui, ijtihad, dan tafsir yang benar dalam bentuk hasil pemikiran yang menyeluruh tentang jagad raya, manusia, masyarakat dan bangsa, pengetahuan kemanusiaan dan akhlaq, dan pendapat tersebut. semata-mata merujuk pada dasar pendidikan Islam, yaitu al-Qur'an dan al-Hadis. ${ }^{11}$

${ }^{9}$ Abu Ahmadi dan Nur Uhbiyati, Ilmu Pendidikan (Jakarta: Rineka Cipta, 1991), 100.

${ }^{10}$ Marimba, Pengantar..., 41.

${ }^{11} \mathrm{Omar}$ Muhammad dan al-Toumy al-Syaibani (ter). Falsafah al-tarbiyah 


\section{Dinamika Institusi Pendidikan Islam}

Pendidikan Islam secara kelembagaan mengalami perubahan secara fluktuatif dari periode satu kepada periode berikutnya. Institusi dan metodologi yang diterapkan disesuaikan dengan perkembangan zaman sehingga pelembagaan pendidikan Islam juga mengalami perubahan, mulai dari masa klasik hingga masa modern. Di samping lembaga yang bersifat umum seperti masjid, terdapat juga lembaga-lembaga lain yang mencerminkan ke-khas-an orientasi sebagai embrio institusi pendidikan Islam.

Menurut Nasr, awalnya pengajaran Islam dilaksanakan di masjid, sehingga pada dekade pertama ini lembaga pengajaran sebagian besar tidak dapat dipisahkan dari masjid. Pengelola dan yang membiayai adalah religious endowment (pemerhati agama). ${ }^{12}$

Dalam sejarah Islam banyak dikenal tempat dan pusat pendidikan dengan jenis, tingkatan, dan sifat yang khas. Pusat pendidikan inilah yang disebut institusi pendidikan Islam masa itu. Dalam buku al-Tarbiyah al-Islamiyah, Nuzumuba, Falsafatuba, Tarikhuba, Ahmad Syalabi menyebutkan tempat-tempat itu sebagai berikut : al-Kuttab, al-Qushur, Hawanit al-Waraqîn, Manaz̧il al-Ulama', al-Badiyah, dan Madrasah. Ia membagi institusi-institusi pendidikan Islam tersebut menjadi dua kelompok, yaitu kelompok sebelum madrasah, dan sesudah madrasah. ${ }^{13}$ Periode madrasah ini dianggap tonggak baru dalam penyelenggaraan pendidikan Islam. Madrasah yang dimaksud ialah madrasah yang dibangun oleh Nizam al-Mulk tahun $459 \mathrm{H}$. Namun demikian, ia juga mengatakan bahwa "institusi-institusi sebelum madrasah itu tetap dipakai sesuai dengan sifat tradisionalnya sekalipun jumlah dan peminatnya sedikit".

al-Islamiyah (Jakarta: Bulan Bintang, 1979), 399.

12Sayyed Hossein Nasr, Science and Civilization in Islam (Cambridge Massachusetts: Harvard University Press, 1908), 65.

${ }^{13}$ Ahmad Syalabi, al-Tarbiyah al-Islamiyah, Nuzumuha, Falsafatuha, Tarikhuba (Kairo: Maktabah al-Nahdah al-Masriyah, 1987), 43. 
Institusi pendidikan Islam mengalami perkembangan, sesuai dengan kebutuhan dan perubahan masyarakat muslim yang ditandai oleh :

1. Perkembangan ilmu. Kaum muslimin pada masa awal membutuhkan pemahaman al-Qur'an sebagai apa adanya, begitu juga membutuhkan keterampilan membaca dan menulis. Ibn Khaldun mencatat bahwa pada awal kedatangan Islam orang-orang Quraisy yang pandai membaca dan menulis hanya berjumlah 17 orang yang semuanya laki-laki. ${ }^{14}$

2. Perkembangan kebutuhan. Pada masa awal Islam, yang menjadi kebutuhan utama ialah mendakwahkan Islam. Karena itu, sasaran pendidikan pada mulanya ditujukan pada orang-orang dewasa. Ketika keadaan semakin baik, penganut Islam semakin banyak dan kuat, terdapatlah kebutuhan untuk melakukan pendidikan untuk anak-anak. Selanjutnya timbul kebutuhan untuk mendidik guru, untuk pengembangan ilmu, dan untuk kebutuhan-kebutuhan masyarakat yang lebih maju, termasuk mempersiapkan pegawai.

Jika diamati lebih lanjut, ternyata tempat-tempat pendidikan di atas kecuali madrasah, bukan tempat yang dipersiapkan khusus untuk pendidikan. Institusi pendidikan Islam ini berkembang secara mandiri dan bersifat evolutif sesuai kebutuhan lokal masyarakat setempat.

Sebelum lahirnya madrasah, masjid merupakan tempat yang paling umum untuk penyelenggaraan pendidikan. Pendidikan yang diselenggarakan di masjid pada waktu itu memiliki keunggulan yang sangat menunjang proses pendidikan, yaitu kebebasan akademik. Di masjid seorang pelajar memang bebas untuk memilih halaqah yang disukai dan bebas pula untuk melakukan perdebatan. Dalam konsep sekarang disebut kebebasan akademik, yaitu kebebasan berfikir dan bereksperimen sesuai keilmuan yang digeluti.

${ }^{14}$ Ibid., 44. 
Proses transformasi institusi pendidikan Islam dari masjid menjadi madrasah telah dibahas sejumlah pakar sejarah Islam melalui berbagai penelitian sejarah, seperti yang dikemukakan oleh George Makdisi. Dalam sejumlah karya kesejarahannya, ia berkesimpulan bahwa perpindahan lembaga pendidikan Islam dari masjid ke madrasah terjadi secara tidak langsung, tetapi melalui tahapan perantara, yaitu masjid-khan. Ada tiga tahapan perkembangan institusi Islam, yaitu masjid, masjid-khan (masjid yang di sekitarnya didirikan asrama bagi pelajar), dan kemudian menjadi madrasah. ${ }^{15}$

Tahap pertama, yaitu periode masjid sebagai institusi pendidikan Islam berlangsung pada abad VIII dan IX. Masjid dalam konteks ini bukanlah masjid yang berfungsi sebagai tempat shalat bagi seluruh penduduk kota, yang biasa dikenal dengan masjid jami'. Masjid yang dimaksud sebagai tempat pendidikan adalah masjid biasa (masjid college) yang di samping untuk tempat shalat juga untuk majlis taklim (pendidikan). Para penguasa seperti Adud al-Daulah (w. 965), al-Sahib Ibn 'Abbad (w. 995), dan Di'lil al-Sijistani (w. 965) merupakan pelopor yang mendukung perkembangan masjid untuk pendidikan ini.

Tahap kedua adalah lembaga masjid-khan, yaitu masjid yang dilengkapi dengan bangunan khan (asrama, pemondokan) yang masih bergandengan dengan masjid. Berbeda dengan masjid biasa, masjid khan menyediakan tempat penginapan yang cukup representatif bagi para pelajar yang datang dari berbagai kota. Tahap ini mencapai perkembangan yang sangat pesat pada abad ke-10. Menurut Makdisi, Badr b. Hasanawaih al-Kurdi (w. 1015) yang menjadi gubernur di beberapa wilayah di bawah kekuasaan Adud al-Daulah mendirikan sekitar 3.000 masjid khan.

Setelah dua tahap perkembangan di atas muncullah madrasah yang khusus diperuntukkan sebagai lembaga pendidikan. Madrasah dengan demikian menyatukan kelembagaan masjid-

${ }^{15}$ George Makdisi, The Rise of Colleges: Institution of Learning in Islam and the West (Edinburgh: Edinburgh University Press, 1981), 27. 
biasa dengan masjid-khan. Kompleks madrasah terdiri dari ruang belajar, ruang pondokan, dan masjid. Menurut Makdisi, perkembangan madrasah dalam polanya yang utuh dan kongkrit dipelopori oleh Nizam al-Mulk.

Perkembangan madrasah pada awal modern ditandai dengan berkembangnya madrasah di Timur Tengah. Di antara para pengelolanya adalah Nizam al-Mulk (456-485 H./1063 M.), Nur al-Din Zanky (541-569 H./1146-1174 M.), Salahuddin al-Ayyubi (564-589 H./1169-1193 M.), dan al-Mustansir bi al-Lâh (623-640 H./1226-1242 M.).

Terakhir tahun 1334 H. Syarif al-Husayn Ibn Ali al-Hashimi mendirikan madrasah al-Hashimiya al-Khairiya menggantikan madrasah al-Rashidiya yang sebelumnya (1903 M./1326 H.) didirikan oleh kerajaan Uthmani di Turki. Berbeda dengan madrasah paling awal yang didirikan di Mekah yang dibiayai secara perorangan. Pada akhir abad VI Hijriyah (antara 571 atau 591 H.) al-Afif 'Abd al-Lah al-Arsufi mendirikan madrasah di dekat Masjid al-Haram, di depan Bab al-'Umra. Begitu juga dengan berdirinya madrasah al-Saulatiyah (1291 H), dan madrasah Dar al-Faizin (1304 H).

Modernisasi pendidikan Islam di timur tengah masa modern ini juga terjadi di Mekah meski masih tingkat dasar. Sebab hingga pertengahan abad XX Mekah belum mengenal pendidikan tinggi. Perguruan Tinggi dalam perspektif modern dikenal di Mekah mulai tahun 1949 M dengan didirikan Kulliyat al-Shari'a wa al Dirasat al-Islamiyah. ${ }^{16}$ Sedangkan di Mesir pelembagaan pendidikan Islam dalam bentuk madrasah dan perguruan tinggi, yaitu al-Azhar.

Para pemikir modernisasi di Timur Tengah juga bermunculan pada masa pelembagaan madrasah ini. Misalnya, di Damaskus, Bairut dan Bagdad muncul para scholars yaitu, Jamal al-Din al-Qasimi (1866-1914), Tahir al-Jaza'iri (1852-1920), 'Abd

\footnotetext{
${ }^{16}$ Saidun Fiddaroini, "Pelembagaan Studi Islam dari Timur Tengah", dalam Akademika, vol. 15, no. 1 (September, 2004), 36.
} 
al-Qadir al-Magribi (1867-1956), dan Mahmud Syukri al-Alusi 91857-1924). Para pemikir ini dikenal pereformasi pendidikan yang bertujuan menunjukkan modernisasi dalam pemikiran Islam, termasuk institusi bernama madrasah. ${ }^{17}$

Jika dianalisis, proses pelembagaan madrasah berlangsung secara evolutif dan disesuaikan dengan perkembangan masyarakat pada masa tersebut. Pada awalnya, institusi pendidikan berupa masjid, masjid-khan dan muncullah lembaga madrasah. Madrasah pada masa itu juga sudah ada madrasah model atau madrasah unggulan sesuai dinamika masyarakat saat itu. Madrasah Nizhamiyah merupakan bentuk madrasah model dan unggulan pada masa itu.

\section{Dinamika Metodologi Pendidikan Islam di Madrasah}

Selain terjadi perkembangan kelembagaan, di madrasah juga terjadi dinamika metodologi pembelajaran. Pada awalnya, pengajaran yang dilaksanakan adalah belajar membaca dan menulis. Namun setelah qurra' dan buffazh mulai bermunculan maka berkembang menjadi belajar dan mengajar al-Qur'an dan pokok-pokok ajaran agama. Setelah itu, kecenderungan metode pengajaran pendidikan Islam adalah untuk mengajarkan tulisbaca dengan materi umum dan mengajarkan tulis-baca plus materi al-Qur'an dan ajaran-ajaran agama. ${ }^{18}$

Transformasi metodologis pertama dan strategis yang terjadi dengan kehadiran Islam adalah perubahan dari tradisi interaksi menggunakan "bahasa lisan" ke yang dilengkapi dengan "baca dan tulis" (literacy). Pada era sebelum kebangkitan madrasah, metode yang diterapkan pada halaqah atau majelis di masjid atau di tempat-tempat lain sangat bervariasi, mulai dari metodemetode yang memorize sampai metode berpikir bebas atau rasional. Ini bisa dilihat antara lain dengan penerapan metode

${ }^{17}$ Esposito, The Oxford..., 119.

18Ibid., 48. 
mendengar dan menghafal, sampai dengan metode disputation atau perdebatan terbuka dan penelitian-penelitian eksperimental pada berbagai pusat pengetahuan kala itu.

Setelah era kebangkitan madrasah, secara metodologis pendidikan Islam cenderung berjalan dalam dua arah. Pertama, berjalan ke arah penerapan metode yang didominasi memorize, mengikuti sistem patronase khususnya dari pihak yang berkepentingan secara politis. Pada arah ini, Fazlur Rahman menunjuk sistem madrasah, katanya, "sistem madrasah yang secara luas didasarkan pada sponsor dan kontrol negara, umumnya telah dipandang sebagai sebab kemunduran dan kemacetan ilmu pengetahuan dan kesarjanaan Islam". ${ }^{19}$

Kecenderungan kedua, berjalan ke arah penerapan metode yang tetap bernuansa beragam dan berpikir bebas (rasional). Untuk jenis ini, Fazlur Rahman menunjuk lembaga-lembaga ilmu pengetahuan "non-formal", yang cenderung hanya didukung oleh individu-individu yang memang sangat mencintai ilmu, tapi terabaikan baik oleh sistem kemasyarakatan maupun pemerintahan. Dalam hal ini, sebagai contoh yang ekstern Fazlur Rahman menunjuk kisah Dar al-Hikmah (House of Wisdom) yang didirikan Dinasti Fatimiyah di Kairo pada 395 H. ${ }^{20}$

Pada masa-masa selanjutnya sampai masa modern, proses belajar mengajar dalam dunia pendidikan Islam, selain masih ada yang mempertahankan pola lama, sudah mulai melakukan adaptasi dari sistem yang dikembangkan dalam dunia pendidikan modern Barat, baik secara institusional maupun metodologis.

\section{Dinamika Madrasah di Indonesia}

Keberadaan madrasah sebagai lembaga pendidikan Islam di Indonesia telah ada pada saat Islam masuk di Indonesia. Bahkan

${ }^{19}$ Fazlur Rahman, Islam and Modernity: Transformation of an Intellectual Tradition (Chicago \& London: The University of Chicago Press, 1992), 186.

20Ibid., 183. 
saat Indonesia memproklamasikan kemerdekaan, madrasah telah berdiri di pelosok bumi Indonesia. ${ }^{21}$ Keberadaan madrasah didirikan dan dikelola oleh masyarakat secara swadaya, sehingga institusi ini sangat tergantung pada pendirinya.

Mona Abaza dalam bukunya Islamic Education Perceptions and Exchanges Indonesia Student in Cairo, menuliskan perkembangan madrasah di Indonesia berjalan hampir bersamaan dengan proses modernisasi institusi pendidikan Islam di Mesir. ${ }^{22} \mathrm{Hal}$ ini dipengaruhi banyaknya pelajar Indonesia yang melakukan pendirian dan pembaharuan pendidikan Islam melalui madrasah, mulai dari Sumatera, Kalimantan, dan Jawa.

Tokoh perintis madrasah yang terkenal antara lain: (1) Abdullah Ahmad, pendiri madrasah Adabiyah di Minangkabau, Zainuddin Labai (1890-1924) mendirikan madrasah Diniyah Zainuddin yang telah menggunakan sistem kelas. Sementara itu di Jawa ada tokoh K.H. Hasyim Asy'ari yang merintis madrasah melalui pesantren Tebu Ireng Jombang. Dari sisi kelembagaan madrasah dimulai dari pesantren yang diubah fungsi dan kurikulumnya. K.H. Hasyim Asy'ari mulai melakukan pembaharuan metodologi pengajaran dari sorogan dan bandongan menjadi sistem kelas atau klasikal. Inilah yang kemudian dikenal dengan sebutan madrasah.

Madrasah yang didirikan ini dikenal dengan madrasah Salafiyah, sebab materi dan kurikulum yang digunakan mengacu pada pengajaran ilmu agama dan bahasa Arab saja. Namun setelah dipegang K.H. Ilyas ada perubahan mendasar yaitu dengan mengajarkan materi umum, sehingga muncul dua model madrasah, yaitu madrasah diniyah yang hanya mengajarkan materi agama dan model madrasah umum yang mengajarkan materi umum serta dimasuki ajaran agama.

${ }^{21}$ Karel, Beberapa Aspek tentang Islam di Indonesia Abad ke-19 (Jakarta: Bulan Bintang, t.t.), 152.

${ }^{22}$ Mona Abaza, Islamic Education Perceptions and Exchanges in Cairo (t.k.p: Cahier d' Arcipel, 1994), 53. 
Sementara itu, K.H. Ahmad Dahlan juga mendirikan sejumlah madrasah dengan beragam inovasi yang dilakukan. Melalui gerakan organisasi Muhammadiyah yang didirikan tahun 1912, pelopor pembaharuan pendidikan Islam di Indonesia ini mendirikan madrasah Muhammadiyah, Mu'allimin dan Mu'allimat Muhammadiyah, serta sejumlah sekolah lain. Pembaharuan yang dilakukan lebih revolusioner, baik dari sisi kelembagaan maupun metodologi. 23

Akibat manajemen pengelolaan institusi madrasah yang berbeda tersebut, kualitas pendidikan Islam di madrasah juga sangat variatif, sehingga penguatan dan perbaikan dalam rangka peningkatan mutu pendidikan Islam, baik secara institusi maupun metodologi sangat diperlukan.

Selama ini pemerintah telah melakukan usaha perbaikan dan penguatan lembaga dan metodologi dalam sistem pendidikan madrasah. Namun perkembangan yang terjadi di masyarakat menunjukkan hasil yang belum optimal. Manajemen madrasah masih bersifat parsial dan belum menemukan model ideal dalam pengelolaannya.

Sebagai konsekwensi perkembangan zaman, madrasah pun mengalami dinamika institusi dan metodologi. Pada dekade akhir-akhir ini secara institusi madrasah dikembangkan menjadi institusi yang kompetitif dengan lembaga lain. Ada madrasah unggulan, madrasah model, serta bentuk lainnya. Secara keseluruhan, jumlah madrasah model di Indonesia ada 128 madrasah. Perubahan pengelolaan manajemen pendidikan Islam ini merupakan bentuk respon dan adaptasi dengan kebutuhan dan perkembangan masyarakat. Sebab jika pendidikan Islam tidak dikelola secara dinamis akan ketinggalan dengan perkembangan masyarakat yang sangat cepat, dan keragaman lembaga madrasah ternyata belum mampu menduduki kualitas, posisi, dan peran yang dicita-citakan konsep pendidikan Islam,

23Ibid., 106. 
sehingga madrasah belum bisa menjadi pendidikan alternatif yang berkualitas dan menjanjikan masa depan generasi. ${ }^{24}$

Secara historis, pendidikan Islam awalnya berlangsung di masjid, kuttab atau maktab, kemudian menjadi pesantren, dan terlembaga menjadi madrasah. Ini artinya kelembagaan pendidikan Islam diawali dengan proses pembelajaran di rumah kyai, masjid, pesantren dan kemudian menjadi madrasah. Hal ini menunjukkan bahwa adanya proses perubahan dari masa ke masa yang menarik untuk dikaji.

Fenomena terkini perkembangan madrasah di Indonesia adalah banyaknya sekolah unggulan (madrasah model). Madrasah model itu ditetapkan oleh Departemen Agama untuk merangsang pengembangan madrasah, baik dari sisi institusi maupun metodologi. ${ }^{25}$ Tujuan yang ingin dicapai adalah agar madrasah tersebut menjadi "model" bagi madrasah lain di sekitarnya. Dalam kaitan itu, Departemen Agama dengan menggunakan dana pinjaman lunak (loan) dari Asian Development Bank (ADB), dan telah menetapkan sejumlah madrasah pada tingkat Madrasah Ibtidaiyah Negeri (MIN) dan Madrasah Tsanawiyah Negeri (MTsN) menjadi madrasah model. ${ }^{26}$

Program madrasah model ini dimulai tahun 1993 melalui JSEP (Junior Secondary Education), dan tahun 1998 diteruskan dengna program BEP (Basic Education Program) untuk MI dan MTs. Pada tahun 2000 dikembangkan melalui DMAP (Development of Madrasah Aliyah Project) untuk MA. Pada saat ini jumlah madrasah model telah mencapai 128 madrasah, dengan rincian $24 \mathrm{MIN}, 69 \mathrm{MTsN}$, dan $35 \mathrm{MAN} .^{27}$ 209.

${ }^{24}$ Malik Fadjar, Holistika Pemikiran Islam (Jakarta: Rajawali Press, 2005),

${ }^{25}$ Departemen Agama RI, Pedoman Pelaksanaan Pengembangan dan Pengelolaan Madrasah Model (Jakarta: Dirjen Binbaga \& Binrua, 1998), 1.

26Berdasarkan Surat Keputusan Direktur Jendral Pembinaan Kelembagaan Agama Islam Nomor E/242A/1999 tanggal 2 Agustus 1999.

27Puslitbang Pendidikan Agma dan Keagamaan, "Efektivitas 
Sementara itu, hasil penelitian Balitbang Depag tahun 2003 menunjukkan bahwa penyelenggaraan program madrasah model relatif efektif terutama untuk meningkatkan kualitas manajemen, profesionalitas guru, sarana prasarana, dan out put pembelajaran. Namun belum cukup efektif untuk mendorong peningkatan mutu madrasah di sekitarnya.

Deskripsi di atas menunjukkan bahwa madrasah di Indonesia telah mengalami perkembangan, baik dari sisi kelembagaan maupun metodologi. Perkembangan itu disesuaikan dengan tuntutan masyarakat terhadap keberadaan madrasah. Lebih jelasnya alur pemikiran dinamika madrasah adalah sebagai berikut:

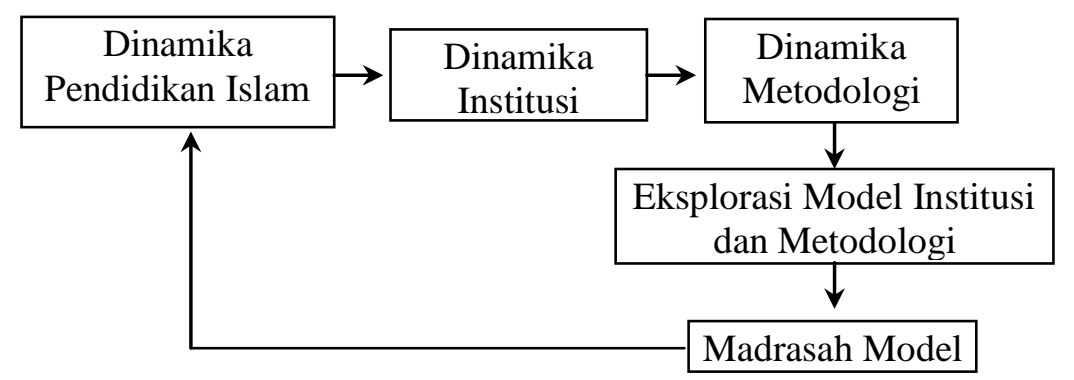

\section{Catatan Akhir}

Pendidikan Islam mengalami perkembangan yang fluktuatif sejak zaman klasik hingga zaman modern, termasuk di Indonesia. Dinamika yang berkembang dan mengalami perubahan ada dua hal, yaitu dinamika kelembagaan dan dinamika metodologi. Dari sisi dinamika kelembagaan, institusi pendidikan Islam terbentuk melalui tiga tahapan, yaitu masjid, masjid khan dan menjadi madrasah. Sedangkan di Indonesia madrasah terbentuk dari pengajaran di rumah kyai, masjid, pesantren, dan kemudian menjadi madrasah.

Penyelenggaraan Madrasah
http://www.depag.web.id/research/pendidikan/73/, Diakses


Dari sisi dinamika metodologi, pendidikan Islam di madrasah diawali dengan metode ceramah, menghafal, dan diskusi terbuka. Sedangkan metode yang berkembang di Indonesia ialah metode ceramah dengan sistem sorogan, bandongan, dan klasikal.

Dinamika kelembagaan dan metodologi telah menjadikan madrasah memiliki ciri khas dan karakteristik tersendiri, sehingga muncullah madrasah unggulan dan madrasah model. Madrasah model memiliki sistem pengelolaan lebih inovatif dan profesional, baik dari sisi sumberdaya manusia maupun sarana prasarana lainnya. Madrasah model ini sebetulnya telah ada sejak awal perkembangan Islam. Dalam sejarah ada madrasah Nizhamiyah, Madrasah Mansyiriyah, dan madrasah lainnya.

Madrasah model yang dikembangkan pada setiap periode memiliki tujuan agar madrasah dikelola sesuai kebutuhan dan adaptif terhadap perkembagan masyarakat. Madrasah model yang dikembangkan di Indonesia memiliki tujuan agar memiliki daya saing dari sisi kualitas maupun kuantitas. Mulai dari sistem kelambagaan hingga metodologi pembelajaran yang diterapkan.

\section{Daftar Pustaka}

A.S. Tritton, Materials on Muslim Education in the Middle Ages (London: Luzac\&Co, 1957).

Abu Ahmadi \& Nur Uhbiyati, Ilmu Pendidikan (Jakarta: Rineka Cipta, 1991).

Ahmad D. Marimba, Pengantar Filsafat Pendidikan Islam (Bandung: Al Ma'arif, 1981).

Ahmad Syalabi al-Tarbiyah al-Islamiyah, Nuzumuba, Falsafatuba, Tarikhuba (Kairo: Maktabah al-Nahdah al-Masriyah, 1987).

Departemen Agama RI, Pedoman Pelaksanaan Pengembangan dan Pengelolaan Madrasah Model. Jakarta: Dirjen Binbaga \& Binrua, 1998. 
Fazlur Rahman, Islam and Modernity: Transformation of an Intellectual Tradition (Chicago \& London: The University of Chicago Press, 1992).

George Makdisi, The Rise of Colleges: Institution of Learning in Islam and the West (Edinburgh: Edinburgh University Press, 1981).

John L. Esposito, The Oxford Encyclopedia of the Modern Islamic World (New York: Oxford University, 1995).

Karel A. Steenbrink, Beberapa Aspek tentang Islam di Indonesia Abad ke-19 (Jakarta: Bulan Bintang, t.t.).

M. Arifin, Kapita Selekta Pendidikan Islam Dan Umum (Jakarta: Bumi Aksara, 1995).

Maksum, Madrasah: Sejarah dan Perkembangannya (Jakarta: Logos Wacana Ilmu, 1999).

Malik Fadjar, Holistika Pemikiran Islam (Jakarta: Rajawali Press, 2005).

Mona Abaza, Islamic Education Perceptions and Exchanges in Cairo (t.k.p: Cahier d' Arcipel, 1994).

Omar Muhammad \& al-Toumy al-Syaibani (ter.), Falsafah altarbiyah al-Islamiyah (Jakarta: Bulan Bintang, 1979).

Puslitbang Pendidikan Agama dan Keagamaan, "Efektivitas Penyelenggaraan Madrasah Model", dalam http:/ / www.depag.web.id/research/pendidikan/73/, diakses 23 April 2008.

Saidun Fiddaroini, "Pelembagaan Studi Islam dari Timur Tengah", dalam Akademika, vol. 15 no. 1, September, 2004. Sayyed Hossein Nasr, Science and Civilization in Islam (Cambridge Massachusetts: Harvard University Press, 1908).

Surat Keputusan Direktur Jendral Pembinaan Kelembagaan Agama Islam Nomor E/242A/1999 tanggal 2 Agustus 1999. Yusuf Qardhawi Pendidikan Islam dan Madrasab Hasan Al-Banna, ter. Bustani A. Ghani dan Zainal Abidin Ahmad (Jakarta: Bulan Bintang, 1980).

Zuhairini (et. al.), Metodologi Pendidikan Agama (Solo: Ramadhani, 1993). 